\title{
Sensor system to determine the thermal parameters of the materials
}

\author{
Chudzik Stanislaw, Grys Slawomir, Minkina Waldemar \\ Czestochowa University of Technology, Institute of Electronics and Control Systems \\ Al. Armii Krajowej 17, 42-200 Czestochowa, POLAND, tel.: (+48 34) 3250883, (+48 34) 3250819, \\ fax (+48 34) 3250821, e-mail: chudzik@el.pcz.czest.pl, grys@el.pcz.czest.pl, minkina@el.pcz.czest.pl
}

\begin{abstract}
The authors present simulation results of a portable system designed for measuring thermal parameters of materials, mainly widespread thermal insulation materials. The proposition is to use an auxiliary thermometer and a trained artificial neural network to determine parameters of thermal insulation materials. The network is trained on data extracted from a model of a nonstationary heat flow process in the sample of material with a hot probe and auxiliary thermometer, based on a two-dimensional heatconduction model and including heat capacity of the probe handle. To solve the system of partial differential equations describing the model, the finite element method (FEM) was applied. The artificial neural network (ANN) is used to estimate coefficients of the inverse heat conduction problem for solid. The network determines values of the effective thermal conductivity and effective thermal diffusivity on the basis of temperature responses of the hot probe and auxiliary thermometer. Several configurations were evaluated during selection of optimal ANN architecture. The influence of measuring errors on identified values of the thermal parameters was also analyzed using the Monte Carlo technique. All calculations like FEM, training and testing processes as well as the error sensitivity analysis were conducted in the Matlab environment. The proposed method of parameters testing is suitable for temporary measurements in a building site or factory.
\end{abstract}

\section{Introduction}

The existing methods of determination of material's thermal parameters, i.e.: heat diffusivity coefficient $a$, $\mathrm{m}^{2} / \mathrm{s}$, heat conductivity coefficient $k, \mathrm{~W} /\left(\mathrm{m}^{2} \cdot \mathrm{K}\right)$ and specific heat $c_{p}, \mathrm{~J} /(\mathrm{kg} \cdot \mathrm{K})$, are based mainly on stationary heat transfer conditions [1-5]. These methods allow determining only a single thermophysical parameter of the tested material. They require the use of big and heavy measuring systems and a long period of time to conduct the measurement. The authors do not know a commercial solution of portable measuring system which, in relatively short time, could assess fulfilling the requirements by insulating materials delivered to a building site or leaving the factory from the point of view of thermal conductivity. Therefore, it seems to be crucial to work on design of such a measuring system. The research in this field concentrates, among other things, on possibility of application of artificial neural networks to solve the coefficient inverse problem of diffusion process. This paper is also concentrated on this issue and presents some results obtained during realization of the research grant.

\section{Heat diffusion in the material with inserted hot probe}

The proposed method is based on the classic transient line heat source (LHS) method, called sometimes the hot wire method or the probe method [6-9]. The LHS method is usually used to determine heat conductivity of loose materials or viscous liquids [10-13]. In the case of measurement of thermoinsulation material's properties using the hot probe, the known solutions based on approximate solution of the Fourier equation, commonly used, are inaccurate. The conditions mentioned there, e.g. [7, $8,10,12]$, cannot be satisfied in general. Moreover, the heat capacity of the hot probe and the testing sample of material are comparable. So, our proposition of the measurement system with the hot probe consists in evaluating three thermal parameters simultaneously. It is sufficient to determine two of them, because they are related by equation:

$$
a=\frac{k}{\rho \cdot c_{p}}
$$

The measurement system should record the temperature changes at the heat probe $T_{H}$ and auxiliary thermometer $T_{X}$. The proposed distance between the hot probe and the thermometer is $8 \mathrm{~mm}-$ Fig. $1 \mathrm{a}$. 
a)

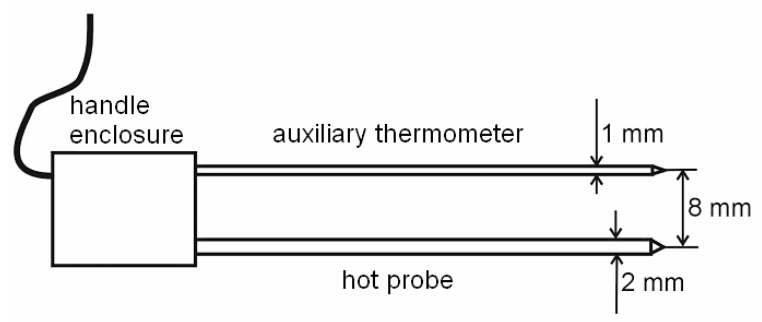

b)

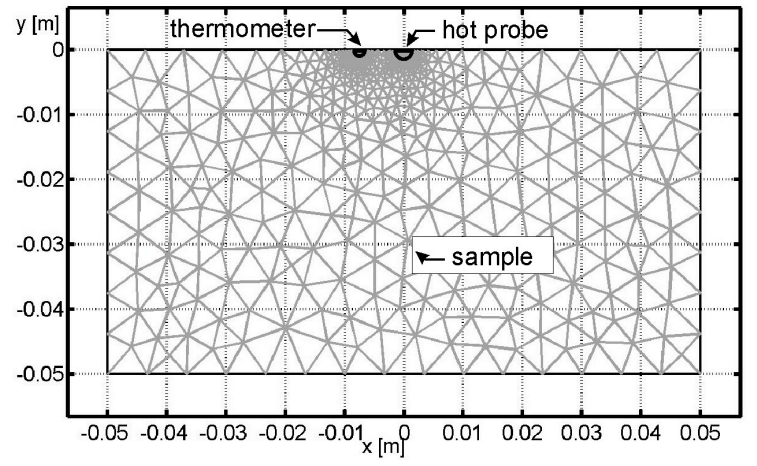

Fig. 1. Predesign of thermal probe (a) and a half section of sample with discrete mesh (b)

To obtain the temperature field in the sample of material with inserted hot probe, the finite element method (FEM) was applied [14]. In a two-dimensional XY co-ordinate, the temperature field, assuming the simplified boundary condition $\partial T / \partial x=0$, was calculated using the Partial Differential Equation Toolbox integrated with the Matlab environment. The values of thermal parameters of the material sample, made of foamed polystyrene, were set to: $a=2.3 \cdot 10^{-6} \mathrm{~m}^{2} / \mathrm{s}, k=0.04 \mathrm{~W} /(\mathrm{m} \cdot \mathrm{K})$. These values ensure negligible influence of the boundary condition, hence the modelled sample can be treated as infinitely extensive. The auxiliary thermometer placed in the tested probe can disturb the thermal field, therefore its presence should be included in the model. The assumed dimensions are as follows: diameter of hot probe is $2 \mathrm{~mm}$ and diameter of the auxiliary thermometer is $1 \mathrm{~mm}$. Thermal parameters of the hot probe, which is made of copper, are $a=116 \cdot 10^{-6} \mathrm{~m}^{2} / \mathrm{s}, k=401 \mathrm{~W} /(\mathrm{m} \cdot \mathrm{K})$ and the thermal parameters of the auxiliary thermometer, which is made of stainless steel, are $3,88 \cdot 10^{-6} \mathrm{~m}^{2} / \mathrm{s}$ and $k=15 \mathrm{~W} /(\mathrm{m} \cdot \mathrm{K})$. These values were taken from [15]. A half section of the sample with the thermal probe and discrete mesh is presented in Fig. 1b. The determination of heat diffusion by means of minimization of the mean squared error was presented in previous papers [4,16]. Its advantages are the possibility of taking into consideration arbitrary chosen, boundary conditions variable during data collecting and input temperature profile during sample heating. The disadvantage is heavy relatively computational burden. In this work, it is attempted to investigate usability of the neural network, presented in Fig. 2, in solving the coefficient inverse problem [17-20] as an alternative to the classical solutions.

\section{Artificial neural network in inverse problem solution}

Using mathematical model of heat diffusion and FEM there were generated training vectors of nine selected instantaneous values of the temperature responses of the hot probe $T_{H}(t)$ and the auxiliary thermometer $T_{X}(t)$ in the sample for $10 \times 10$ combinations of values of $a \in\langle 1.0 \div 3.0\rangle \cdot 10^{-6} \mathrm{~m}^{2} / \mathrm{s}$ and $k \in\langle 3.0 \div 5.0\rangle \cdot 10^{-2} \mathrm{~W} /(\mathrm{m} \cdot \mathrm{K})$ for time interval $100 \mathrm{~s}$. The training input vectors of the instantaneous values of the temperature $T_{H}(t)$ and $T_{X}(t)$ is shown in Fig. 3.

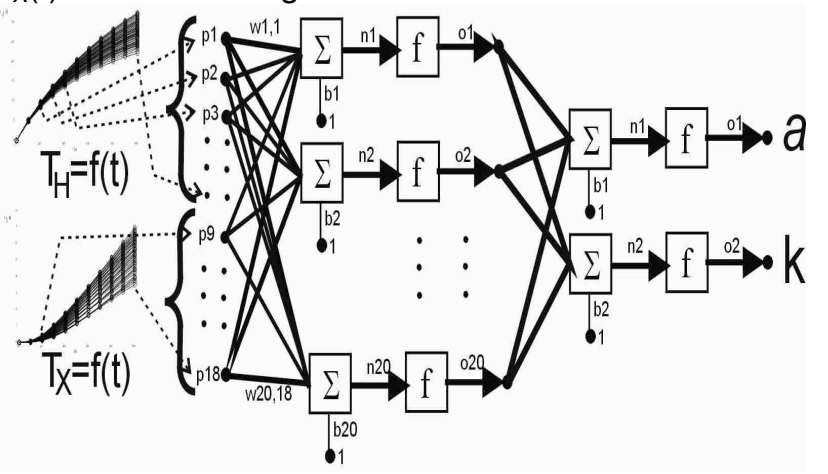

Fig. 2. A hypothetical architecture of the neural network with input and output quantities

To verify whether the network response is correct for intermediate values of $a$ and $k$ from the ranges defined above, the responses were simulated for 100 values of heat diffusivity coefficient $a$ from the range $a \in\langle 1.0 ; 3.0\rangle \cdot 10^{-6} \mathrm{~m}^{2} / \mathrm{s}$ and 100 values of heat conductivity coefficient $k$ from the range and $k \in\langle 3.0 ; 5.0\rangle \cdot 10^{-2} \mathrm{~m}^{2} / \mathrm{s}$. Consequently, in general, there were generated 10000 testing vectors. 
a)

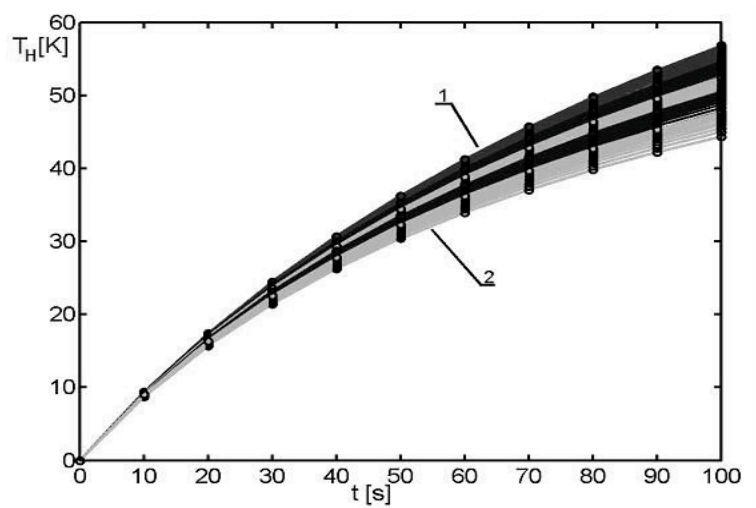

b)

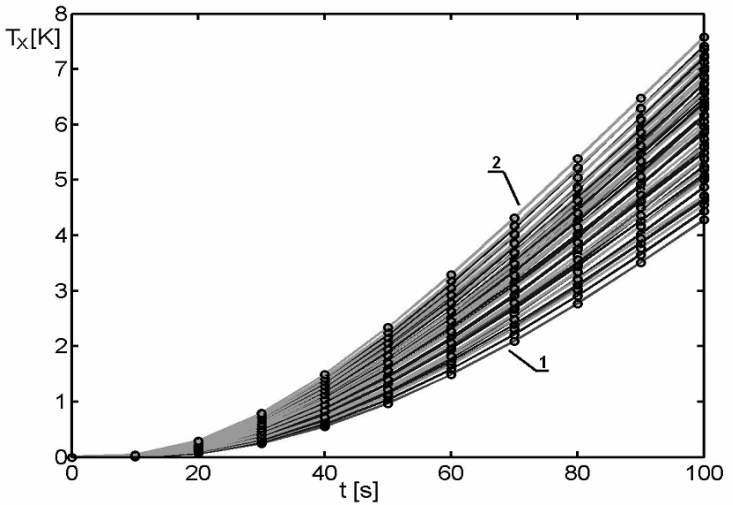

Fig. 3. Examples of the training vectors of the instantaneous values of the temperature of: a) the heating probe $T_{H}(t)$, b) the temperature of the auxiliary thermometer $T_{X}(t)$, where 1) $a=3,0 \cdot 10^{-6} \mathrm{~m}^{2} / \mathrm{s}, k=$ $5,0 \cdot 10^{-2} \mathrm{~W} /(\mathrm{m} \cdot \mathrm{K})$; 2) $a=1,0 \cdot 10^{-6} \mathrm{~m}^{2} / \mathrm{s}, k=3,0 \cdot 10^{-2} \mathrm{~W} /(\mathrm{m} \cdot \mathrm{K})$.

From the other side, the network should be able to approximate the model of heat diffusion with acceptable accuracy and simultaneously with low input error sensitivity. Many of the most popular ANN architectures were tested. Numbers from 1-10 associated with the ANN architecture in the list presented below are adequate to these included in table 1 and 2 . The following networks were tested:

- Neural networks with radial basis functions (RBFNN):

1) classical RBFNN,

2) generalized regression GRNN,

3) RBFNN with given error goal,

- Classical nonlinear neural network:

4) three-layer classical nonlinear network with 20 neurons in first hidden layer and 10 neurons in second hidden layer, 25 training epochs,

5) three-layer classical nonlinear network with 20 neurons in first hidden layer and 10 neurons in second hidden layer, 1000 training epochs,

6) two-layer classical nonlinear network with 20 neurons in hidden layer, 25 training epochs,

7) two-layer classical nonlinear network with 20 neurons in hidden layer, 50 training epochs,

8) two-layer classical nonlinear network with 20 neurons in hidden layer, 1000 training epochs,

9) two-layer classical nonlinear network with 10 neurons in hidden layer, 25 training epochs,

10) two-layer classical nonlinear network with 10 neurons in hidden layer, 50 training epochs.

Because, the volume of this paper is limited, only results of training and testing for classical RBFNN (no. 1) are graphically presented in Fig. 4, for instance. All considered cases are summarized in table 1.

a)

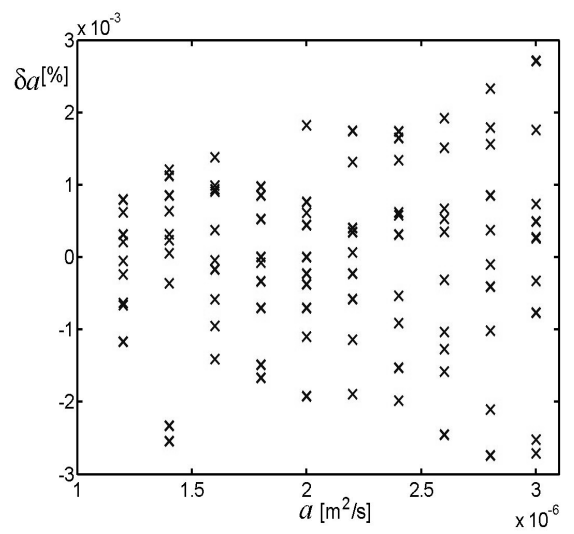

b)

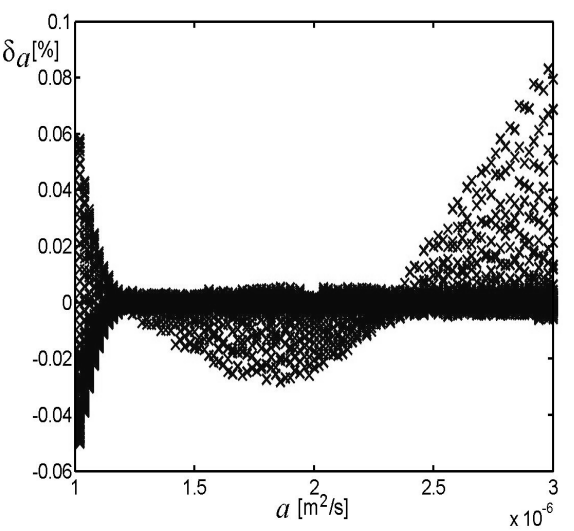

c)

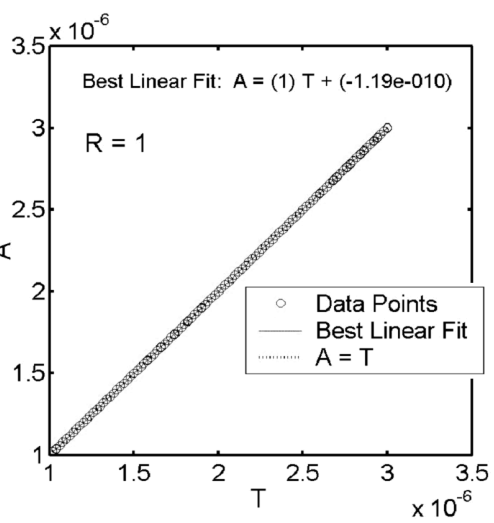

Fig. 4. Relative error of the classical RBF network response $\delta a$ for thermal diffusivity for training stage (a), testing stage (b) and linear regression method matching (c), where: T - given output value, A - network answer, $R$ - correlation coefficient

In the case of the classical radial basis function neural network, the results acknowledge its possibility to solve the inverse problem. For some learning parameters, the output error is negligible for training and testing data - marked data in table 1. However, the network structure of 100 RBF neurons is relatively big. 
In the case of the GRNN, the "over fitting effect" was observed. Reduction of amount of the neurons or decreasing the size of training vector can remove this disadvantage.

Table 1. Results of training and testing stages for given networks' architectures

\begin{tabular}{|c|c|c|c|c|c|c|c|c|c|c|}
\hline \multirow{4}{*}{$\begin{array}{l}\text { ANN } \\
\text { archite } \\
\text { cture }\end{array}$} & \multirow{2}{*}{\multicolumn{2}{|c|}{$\begin{array}{c}\text { Training stage } \\
\text { of neural network }\end{array}$}} & \multicolumn{8}{|c|}{ Testing stage of neural network } \\
\hline & & & \multirow{3}{*}{$\left|\delta a_{\max }\right| \%$} & \multirow{3}{*}{$\left|\delta k_{\max }\right| \%$} & \multicolumn{3}{|c|}{ Heat diffusivity $a$} & \multicolumn{3}{|c|}{ Heat conductivity $k$} \\
\hline & \multirow{2}{*}{$\left|\delta a_{\max }\right| \%$} & \multirow{2}{*}{$\left|\delta k_{\max }\right| \%$} & & & \multirow{2}{*}{$\mathrm{R}$} & \multicolumn{2}{|c|}{$A=a T+b$} & \multirow{2}{*}{$\mathrm{R}$} & \multicolumn{2}{|c|}{$\mathrm{A}=\mathrm{aT}+\mathrm{b}$} \\
\hline & & & & & & A & $\mathrm{b}$ & & $a$ & $\mathrm{~b}$ \\
\hline 1) & $2,8 \cdot 10^{-3}$ & $1,7 \cdot 10^{-5}$ & 0,08 & $2,4 \cdot 10^{-3}$ & 1 & 1 & $-1,19 \cdot 10^{-10}$ & 1 & 1 & $-2,34 \cdot 10^{-8}$ \\
\hline 2) & 2,5 & 0,23 & 26 & 6 & 0,989 & 0,956 & $-1,19 \cdot 10^{-7}$ & 0,997 & 0,979 & $9,87 \cdot 10^{-4}$ \\
\hline 3) & 0,08 & 0,07 & 0,8 & 1,2 & 1 & 1 & $5,43 \cdot 10^{-10}$ & 1 & 0,998 & $8,88 \cdot 10^{-5}$ \\
\hline 4) & 0,01 & $5,0 \cdot 10^{-3}$ & 0,6 & 0,08 & 1 & 1 & $4,83 \cdot 10^{-10}$ & 1 & 1 & $6,85 \cdot 10^{-6}$ \\
\hline 5) & $3,8 \cdot 10^{-3}$ & $1,5 \cdot 10^{-3}$ & 0,03 & 0,01 & 1 & 1 & $-4,50 \cdot 10^{-11}$ & 1 & 1 & $5,97 \cdot 10^{-7}$ \\
\hline 6) & 0,01 & $3,0 \cdot 10^{-3}$ & 0,5 & 0,09 & 1 & 1 & $3,77 \cdot 10^{-10}$ & 1 & 1 & $1,29 \cdot 10^{-6}$ \\
\hline 7) & 0,5 & 0,18 & 1,5 & 0,4 & 1 & 1 & $-2,16 \cdot 10^{-13}$ & 1 & 1 & $1,04 \cdot 10^{-5}$ \\
\hline 8) & 0,02 & 0,01 & 0,4 & 0,06 & 1 & 1 & $-5,00 \cdot 10^{-10}$ & 1 & 1 & $3,39 \cdot 10^{-6}$ \\
\hline 9) & 0,2 & 0,1 & 1,1 & 1,1 & 1 & 1 & $6,87 \cdot 10^{-10}$ & 1 & 0,999 & $2,20 \cdot 10^{-5}$ \\
\hline 10) & 0,4 & 0,09 & 1,7 & 0,45 & 1 & 1 & $-1,09 \cdot 10^{-9}$ & 1 & 1 & $1,98 \cdot 10^{-5}$ \\
\hline
\end{tabular}

A good solution is application of the RBF network with given error goal, which automatically chooses the number of neurons to draw output error with error goal. Such a solution facilitates looking for an optimal network structure, because of automatic selection of the neurons number. Promising results were obtained also for the classical nonlinear network with the hyperbolic tangent transfer function in input and hidden layers. In the case of the hidden layer there is sufficient to use the linear activity function. A threelayer network obtained the good performance after 25 epochs. Thanks to its flexibility the over fitting did not occur. Taking 1000 epochs, output error was very small, both for learning and testing vector - marked data in table 1. Performance of the two-layer network was also investigated. The output error was in this case was somewhat larger than for the three-layer network but it can be compensated by a longer learning period (more epochs).

Network generalization ability is only one of many conditions that the network must satisfy. A very important issue is determination of sensitivity of the neural network to input quantities disturbance. Good ability of generalization of the chosen network going hand in hand with its small sensitivity must be proved. If it fails, then another network candidate for "optimal network architecture" must be selected and checked.

\section{Sensitivity analysis of neural network to input quantities disturbance}

It was assumed, that the following input quantities have influence on the output quantities $a$ and $k$ : temperature of the hot probe $T_{H}(t)$, temperature of the auxiliary thermometer $T_{X}(t)$, heat power $P_{G}$ supplying the hot probe and distance $r$ between the hot probe and the auxiliary thermometer. A uniform symmetric distribution of probability of all input quantities was assumed with the following half widths: $\Delta T_{H}(t)=0.1 \mathrm{~K}, \Delta T_{X}(t)=0.05 \mathrm{~K}, \Delta P_{G}=1 \mathrm{~mW} / \mathrm{m}, \Delta \mathrm{r}=0.1 \mathrm{~mm}$. The Monte Carlo simulation technique was applied, as effective method in case of big complexity of the mathematical model. Generation of input quantities for $10^{6}$ trials (this number is strongly recommended by [21]) and model calculation for one pair given thermal parameters were taken over 6 days using modern PC computer (year 2008). Hence, the analysis was constrained to the following five combinations of values of $a$ and $k$, treated as "true" values:
a) $a=2.5 \cdot 10^{-6} \mathrm{~m}^{2} / \mathrm{s}$ and $k=4.0 \cdot 10^{-2} \mathrm{~W} /(\mathrm{m} \cdot \mathrm{K})$,
b) $a=1.5 \cdot 10^{-6} \mathrm{~m}^{2} / \mathrm{s}$ and $k=3.3 \cdot 10^{-2} \mathrm{~W} /(\mathrm{m} \cdot \mathrm{K})$,

c) $a=3.5 \cdot 10^{-6} \mathrm{~m}^{2} / \mathrm{s}$ and $k=4.7 \cdot 10^{-2} \mathrm{~W} /(\mathrm{m} \cdot \mathrm{K})$,

e) $a=1.5 \cdot 10^{-6} \mathrm{~m}^{2} / \mathrm{s}$ and $k=4.7 \cdot 10^{-2} \mathrm{~W} /(\mathrm{m} \cdot \mathrm{K})$.

d) $a=3.5 \cdot 10^{-6} \mathrm{~m}^{2} / \mathrm{s}$ and $k=3.3 \cdot 10^{-2} \mathrm{~W} /(\mathrm{m} \cdot \mathrm{K})$,

Letters from a) to e) are used to identify the cases presented in table 2. For each pair of $a$ and $k$ the output value of the network was computed and estimates of distribution function $G(a)$ and $G(k)$ were evaluated. Because, the volume of this paper is limited, only distribution function for two estimated of thermal parameters for classical RBFNN are graphically presented in Fig. 5. All considered cases (10 ANN architectures and 5 combination of $\underline{a}$ i $k$ ) are summarized in table 2 . The following statistical parameters are included: expectation, standard deviation and $95 \%$ coverage interval, understood according to [22]. For better clarity of presented data, the $95 \%$ coverage intervals closest to given ("true") values were additionally marked. The best results were obtained for the RBF networks (no. 1-3). The three-layer ANN (no. 4) was sensitive to input signal disturbances. By taking more epochs, this sensitivity could be significantly reduced. For 1000 epochs, the ANN output error satisfied the design requirements (no. 5) and was comparable to results for the RBF networks. In case of two-layer ANNs the output error was a little bigger than for a three-layer ANN, but increasing the number of learning period epochs and number of neurons in input layer the performance of this network were comparable to the three-layer ANN (no. 8). 
a)

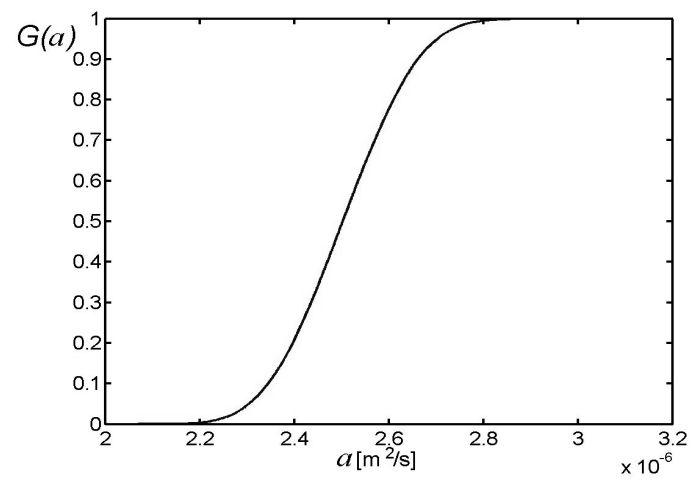

b)

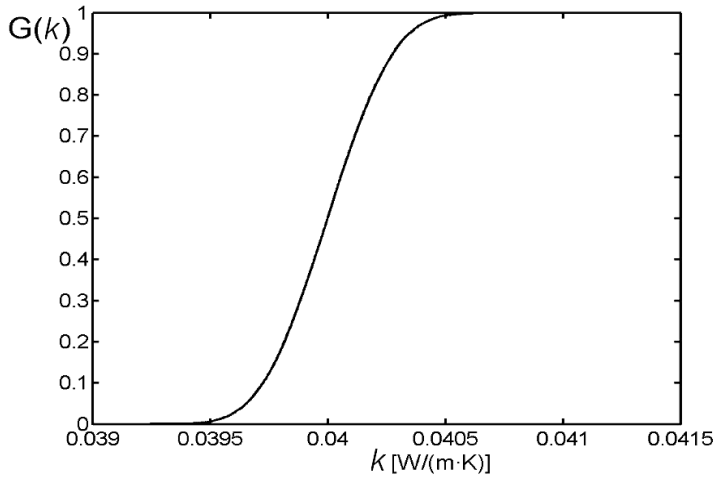

Fig. 5. Distribution function for thermal diffusivity (a) and thermal conductivity (b)

Tab. 2. Results of sensitivity analysis for tested ANN architectures

\begin{tabular}{|c|c|c|c|c|c|c|c|c|c|c|c|c|c|c|c|}
\hline \multirow{2}{*}{$\begin{array}{l}\text { AN } \\
\mathrm{N} \\
\text { arc } \\
\text { hite } \\
\text { ctur } \\
\mathrm{e}\end{array}$} & \multirow[b]{2}{*}{$\begin{array}{c}\text { Give } \\
\mathrm{n} \\
\text { valu } \\
\text { es }\end{array}$} & \multicolumn{3}{|c|}{ Heat diffusivity a $\mathrm{m}^{2} / \mathrm{s}$} & \multicolumn{3}{|c|}{$\begin{array}{l}\text { Heat conductivity } k \\
\mathrm{~W} /(\mathrm{m} \cdot \mathrm{K})\end{array}$} & \multirow{2}{*}{$\begin{array}{c}\mathrm{A} \\
\mathrm{N} \\
\mathrm{N} \\
\text { ar } \\
\text { chi } \\
\text { tec } \\
\text { tur } \\
\mathrm{e}\end{array}$} & \multirow{2}{*}{$\begin{array}{c}\mathrm{Gi} \\
\text { ve } \\
\mathrm{n} \\
\text { val } \\
\text { ue } \\
\mathrm{s}\end{array}$} & \multicolumn{3}{|c|}{ Heat diffusivity a $\mathrm{m}^{2} / \mathrm{s}$} & \multicolumn{3}{|c|}{$\begin{array}{l}\text { Heat conductivity } k \\
\mathrm{~W} /(\mathrm{m} \cdot \mathrm{K})\end{array}$} \\
\hline & & $\begin{array}{c}\text { Expe } \\
\text { ctatio } \\
n \\
\cdot 10^{-6}\end{array}$ & $\begin{array}{c}\text { Stan } \\
\text { dard } \\
\text { devia } \\
\text { tion } \\
\cdot 10^{-7}\end{array}$ & $\begin{array}{c}95 \% \\
\text { coverage } \\
\text { interval } \\
\cdot 10^{-6}\end{array}$ & $\begin{array}{c}\text { Expe } \\
\text { ctati } \\
\text { on } \\
\cdot 10^{-2}\end{array}$ & $\begin{array}{c}\text { Stan } \\
\text { dard } \\
\text { devia } \\
\text { tion } \\
\cdot 10^{-3}\end{array}$ & $\begin{array}{c}95 \% \\
\text { coverage } \\
\text { interval } \\
\cdot 10^{-2}\end{array}$ & & & $\begin{array}{c}\text { Expe } \\
\text { ctatio } \\
n \\
\cdot 10^{-6}\end{array}$ & $\begin{array}{c}\text { Stan } \\
\text { dard } \\
\text { devia } \\
\text { tion } \\
\cdot 10^{-7}\end{array}$ & $\begin{array}{c}95 \% \\
\text { coverage } \\
\text { interval } \\
\cdot 10^{-6}\end{array}$ & $\begin{array}{c}\text { Expe } \\
\text { ctatio } \\
n \\
\cdot 10^{-6}\end{array}$ & $\begin{array}{c}\text { Stan } \\
\text { dard } \\
\text { devia } \\
\text { tion } \\
\cdot 10^{-7}\end{array}$ & $\begin{array}{c}95 \% \\
\text { coverage } \\
\text { interval } \\
\cdot 10^{-6}\end{array}$ \\
\hline \multirow[t]{5}{*}{ 1) } & a) & 50 & & 1 & $\overline{00}$ & 0.21 & $6 ; 4.0$ & \multirow[t]{5}{*}{ 6) } & a) & .40 & 6 & $\overline{71}$ & 4.05 & 3.52 & $.39 ; 4.74$ \\
\hline & b) & 1.50 & 1.26 & 26 & 30 & 0.18 & {$[3.26 ; 3.34$} & & b) & 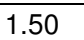 & & & 30 & .67 & $59 ; 3.9$ \\
\hline & c) & 3.50 & 1.13 & 72] & 70 & 0.23 & {$[4.66 ; 4.74]$} & & c) & 47 & & & 67 & 46 & $21 ; 5.12]$ \\
\hline & d) & 3.50 & 1.34 & [3.2 & 30 & 0.18 & [3.26; 3.34] & & d) & 42 & 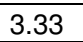 & 40] & 3.28 & 4.27 & $.49 ; 4.12]$ \\
\hline & e) & 1.50 & 0.99 & {$[1$.} & 4.70 & 0.23 & {$[4.65 ; 4.74]$} & & e) & 49 & 1.20 & & 4.70 & 2.76 & {$[4.15 ; 5.19]$} \\
\hline \multirow[t]{5}{*}{ 2) } & a) & 2.51 & & & 00 & 0.04 & {$[3.99 ; 4.01]$} & \multirow[t]{5}{*}{ 7) } & a) & 53 & 0 & & 4.05 & 0.43 & {$[3.97 ; 4.13]$} \\
\hline & b) & 1.52 & 0.42 & & 3.31 & 0.55 & {$[3.22 ; 3.38]$} & & b) & .49 & & 54] & 3.29 & 0.41 & $3.21 ; 3.37]$ \\
\hline & c) & 2.99 & & & 4.60 & 0.02 & {$[4.59 ; 4.60]$} & & c) & 41 & & & 4.56 & 0.40 & {$[4.49 ; 4.64]$} \\
\hline & d) & 97 & & & 3.20 & 0.03 & {$[3$.} & & d) & & & & 3.27 & 0.40 & 3.34] \\
\hline & e) & 1.51 & 0 & & 4.70 & 0.41 & {$[4.64 ; 4.77]$} & & e) & .49 & .2 & & 4.70 & .46 & $.61 ; 4.79]$ \\
\hline \multirow[t]{5}{*}{ 3) } & a) & 50 & & & $\overline{00}$ & 0.23 & {$[3.96 ; 4.04]$} & \multirow[t]{5}{*}{8} & a) & .50 & & & 4.00 & 0.57 & ;4.11] \\
\hline & b) & 1.50 & 0.1 & & 3.30 & 0.21 & {$[3.26 ; 3.33]$} & & b) & .50 & 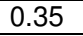 & & 30 & .55 & ;3.41] \\
\hline & (c) & 3.49 & 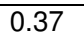 & & 4.70 & 0.25 & {$[4.66 ; 4.75]$} & & c) & 3.5 & & & .70 & .61 & $4.58 ; 4.82$ \\
\hline & d) & 48 & & 57] & 3.30 & 0.21 & {$[3.26 ; 3.33]$} & & d) & 3.50 & & & 30 & .56 & $3.19 ; 3.41$ \\
\hline & e) & 1.50 & 0.12 & {$[1.48$} & 4.70 & 0.24 & {$[4.66 ; 4.74]$} & & e) & 1.50 & 032 & 56] & 4.70 & 0.58 & {$[4.59 ; 4.81]$} \\
\hline \multirow[t]{5}{*}{ 4) } & a) & 2.49 & 3.07 & & 3.98 & 2.82 & {$[3.43 ; 4.53]$} & \multirow[t]{5}{*}{ 9) } & a) & 51 & & & 4.00 & 3.22 & {$[3.38 ; 4.61]$} \\
\hline & b) & 1.52 & 2.49 & {$[1.0$} & 3.28 & 2.87 & {$[2.75 ; 3.83]$} & & b) & 1.51 & 2.26 & 1.93] & 3.30 & 2.87 & {$[2.76 ; 3.83]$} \\
\hline & c) & 3.48 & 1.55 & & 4.70 & 2.56 & {$[4.20 ; 5.14]$} & & c) & 3.52 & 375 & 96] & 4.70 & 3.56 & {$[4.03 ; 5.37]$} \\
\hline & d) & 3.48 & 2.49 & & 3.29 & 2.47 & {$[2.83 ; 3.74]$} & & d) & 3.52 & & & 3.30 & 2.97 & {$[2.73 ; 3.86]$} \\
\hline & e) & 1.50 & 1.61 & {$[1.1$} & 4.68 & 2.36 & {$[4.26 ; 5.14]$} & & e) & 1.50 & 1.82 & $84]$ & 4.69 & 3.16 & {$[4.10 ; 5.31]$} \\
\hline \multirow[t]{5}{*}{ 5) } & a) & 2.50 & 0.63 & & 4.00 & 0.49 & {$[3.90 ; 4.10]$} & \multirow[t]{5}{*}{ 10) } & a) & 2.50 & 07 & $.64]$ & 4.00 & 1.02 & {$[3.81 ; 4.21]$} \\
\hline & b) & 1.50 & 0.66 & & 3.30 & 0.47 & {$[3.21 ; 3.39]$} & & b) & 1.50 & & & 3.30 & 1.07 & {$[3.12 ; 3.49]$} \\
\hline & c) & 50 & & & 4.70 & 0.51 & {$[4.60 ; 4.80]$} & & c) & 3.4 & & & 4.70 & 1.26 & {$[4.48 ; 4.95]$} \\
\hline & d) & 50 & & & 0 & 0.43 & {$[3.21 ; 3.38$} & & d) & 3.4 & & & 3.30 & 0.87 & {$[3.14 ; 3.81]$} \\
\hline & e) & 1.50 & 0.91 & {$[1.42 ; 1.58]$} & 4.70 & 0.56 & {$[4.59 ; 4.81]$} & & e) & 1.50 & 0.68 & {$[1.37 ; 1.63]$} & 4.70 & 1.36 & {$[4.46 ; 4.95$} \\
\hline
\end{tabular}

\section{Conclusion}

Analysis of data presented in previous chapters let us state some conclusions. The proposed method allows estimation of the thermal parameters assuming repeatable environmental conditions. The best ANN architecture was the classical nonlinear feedforward two-layer neural network with 20 neurons with the hyperbolic-tangent transfer function in the hidden layer and two neurons with the linear transfer function in the output layer. The network has 18 inputs and 2 outputs. This network was chosen from others as compromise between generalization ability, architecture simplicity, small output error and small sensitivity to input signal disturbances. The hot probe with the diameter greater than used so far can be applied. It would be easier to use in the industrial regime. Thermoinsulating materials can be tested in a place aimed to assembly them. The proposed solution can significantly reduce the complexity of a measuring system and finally its cost. The system could be based on a relatively cheap and simple, 8/16 bits embedded microcontroller, for instance. The future work will be experimental verification of the proposed method considering many aspects like: material types, dimensions of sample, ANN architectures. 
This work was supported by Ministry of Science and Higher Education of Poland under research grant No. N N505 312933 realized in years 2007-2009.

\section{References}

[1] Y. Bayazitoğlu and M.N. Özişik: "Elements of Heat Transfer" McGraw-Hill Book Company, New York, 1988.

[2] A. Bejan, Heat Transfer. John Wiley \& Sons, New York, 1993.

[3] J. Jurkowski. Y. Jarny and Y. Delanuay: "Estimation of thermal conductivity of thermoplastics under moulding conditions: an apparatus and an inverse algorithm" Int. J. Heat Mass Transfer, vol. 17 (1997), pp. 4169-4181.

[4] W. Minkina and S. Chudzik: "Measurement of Thermal Parameters of Thermoinsulating Materials Instrumentation and Methods (title in Polish is Pomiary parametrow cieplnych materialow termoizolacyjnych - przyrzady $\mathrm{i}$ metody). Publishing House of Czestochowa University of Technology, Czestochowa (Poland), ISBN 83-7193-216-2.

[5] C.E. Platunov: Thermophysical Measurements and Instrumentation (title in Russian is Теплофизические измерения и приборы). Изд. Машиностроение, San Petersburg, 1986.

[6] J. Boer. J. Butter. B. Grosskopf and P. Jeschke: "Hot wire technique for determining high thermal conductivities" Refractories Journal, vol. 55 (1980), pp. 22-28.

[7] A. Bouguerra. O. Ait-Mokhtar. M. Amiri and B. Diop: "Measurement of thermal conductivity, thermal diffusivity and heat capacity of highly porous building materials using transient plane source technique" Int. Comm Heat Mass Transfer, vol. 28 (2001), pp. 1065-1078.

[8] C. Gobbé. S. Iserna and B. Ladevie: "Hot strip method: application to thermal characterisation of orthotropic media" International Journal of Thermal Sciences, vol. 43 (2004), pp. 951-958.

[9] L. Kubicar and V. Bohac: "A Step-wise method for measuring thermophysical parameters of materials" Meas. Sci Technol., vol. 11 (2000), pp. 252-258.

[10] J. Sylos Cintra and W. Santos: "Numerical analysis of sample dimensions in hot wire thermal conductivity measurements" Journal of the European Ceramic Society, vol. 20 (2000), pp. 1871-1875.

[11] M. Al-Homoud: "Performance characteristics and practical applications of common building thermal insulation materials" Building and Environment, vol. 40 (2005), pp. 353-366.

[12] I.H. Tavman and S. Tavman: "Measurement of thermal conductivity of dairy products" Journal of Food Engineering, vol. 41 (1999), pp. 109-114.

[13] G. Ventkaesan and Guang-Pu Jin: "Measurement of thermophysical properties of polyurethane foam insulation during transient method" Int. J. Therm. Sci., vol. 40 (2001), pp. 133-144.

[14] W. Aquino and J. Brigham: "Self-learning finite elements for inverse estimation of thermal constitutive models" International Journal of Heat and Mass Transfer, vol. 49 (2006), pp. 2466-2478.

[15] I.C. Grigoryev, Physical quantities. Handbook (title in Russian is Физические величины, Справочник). Энергоотомиздат, Moscow, 1991.

[16] S. Chudzik and W. Minkina: "Quick quality inspection of thermal parameters of heat-insulating materials" International Conference Material Testing and Research. Nuremberg (Germany), pp. 341347, 8-10 May 2001.

[17] A. Hasiloglu. M. Yilmaz. O. Comakli and I. Ekmekci: "Adaptive neuro-fuzzy modeling of transient heat transfers in circular duct air flow" International Journal of Thermal Sciences, vol. 43, pp. 1075-1090, 2004.

[18] I. Turias. J. Gutie'rrez and P. Galindo: "Modelling the effective thermal conductivity of an unidirectional composite by the use of artificial neural networks" Composites Science and Technology, vol. 65 (2005), pp. 609-619.

[19] S. Chudzik: "Determination of thermal diffusivity of heat-insulating material using neural networks" (title in Polish is Okreslenie wspolczynnika dyfuzyjnosci cieplnej materialow termoizolacyjnych z wykorzystaniem sieci neuronowych) Proc. of $3^{\text {th }}$ Scientific-Technical Conference on Methods and Computer Systems in Automatics and Electrical Engineering. Poraj (Poland), pp. 126-128, 17-19 September 1999.

[20] S. Chudzik S., S. Grys and R. Babka: "Possibility of use of artificial neural networks for solving the coefficient inverse problem" (title in Polish is Mozliwosc wykorzystania sztucznych sieci neuronowych do rozwiazania wspolczynnikowego zagadnienia odwrotnego). Proc. of $4^{\text {th }}$ ScientificTechnical Conference on Methods and Computer Systems in Automatics and Electrical Engineering. Poraj (Poland), pp. 46-48, 17-18 September 2001.

[21] Guide to the Expression of Uncertainty in Measurement. Supplement 1. Numerical Methods for the Propagation of Distributions. Joint Committee for Guides in Metrology. 2004.

[22] Guide to the Expression of Uncertainty in Measurement. BIPM. IEC. IFCC. ISO. IUPAC. IUPAP and OIML. 1995. 